\title{
Neonatal Eye Infections due to Mycoplasma hominis
}

\author{
D. M. JONES,* M.D., M.C.PATH., DIP.BACT.; BARBARA TOBIN, $\dagger$ PH.D., DIP.BACT.
}

Brit. med. F., 1968, 3, $\underline{467-468}$

\begin{abstract}
Cummary : In one year Mycoplasma hominis was isolated from 8 out of 250 clinically infected eyes of newborn infants. This infection occurred in only a small proportion of babies whose mothers carried the organism in the vagina. Probably mycoplasma infection of the eye in neonates is commoner than is realized.
\end{abstract}

\section{Introduction}

Infection of the genital tract by Mycoplasma hominis occurs occasionally as a cause of fever associated with normal deliveries or abortion (Stokes, 1955 ; Slingerland and Morgan, 1952; Tully et al., 1965). The organism has been isolated from the foetus in cases of abortion (Hayflick and Standbridge, 1967 ; Jones, 1967 ; Pease et al., 1967) and also from superficial skin infection of the newborn (Hoogendijk et al., 1965).

This paper reports the isolation of $M$. hominis from the eyes of neonates and describes the relevant clinical features.

\section{Present Investigation}

Procedures.-During one year swabs taken from sticky or infected eyes of babies born in Withington Hospital and submitted to the laboratory for bacterial culture were also examined for the presence of $M$. hominis. Eye swabs were plated on to horse blood agar and chocolate agar and incubated for up to four days in a moist atmosphere. The isolations of $M$. hominis were all made on these unselective media, but in the latter part of this study selective media for the growth of other "large colony" mycoplasmas and T-strain mycoplasmas were also used. The strains of Mycoplasma were identified as M. hominis by the growth-inhibition technique (Clyde, 1964).

Results.-During the period of this study approximately 250 eye swabs were examined; $8(3.2 \%)$ of these yielded a growth of $M$. hominis in the absence of any other bacterial pathogens. The amount of growth varied from a dozen to several hundred colonies, but in most cases about 100 colonies were established on blood agar. No bacteria were seen in Gram-stained films of the eye discharge from any of the babies.

\section{Case Histories}

Case 1.-Aged 18, single, first pregnancy ; membranes ruptured for nine hours before delivery. The left eye of the baby was sticky the day after birth, and M. hominis was isolated from the eye but not from a throat swab. The eye was swabbed with sterile saline, and after 48 hours was no longer sticky though the eyelids were still reddened.

Case 2.-Aged 23 ; separated from husband ; five previous pregnancies; membranes ruptured half an hour before delivery. The baby's eye was sticky on the day following birth and was treated by swabbing with saline.

Case 3.-Aged 21 ; separated from husband ; four previous pregnancies; membranes ruptured for one hour. The baby's eye was sticky for two days and was treated with saline swabbing.

* Consultant Bacteriologist, Withington Hospital, Manchester 20. t Research Assistant, Withington Hospital, Manchester 20.
Case 4.-Aged 24, married, one previous pregnancy; the membranes ruptured 21 hours before delivery. At birth both the baby's eyes were sticky, and this was cured by saline swabbing.

Case 5.-Aged 26, single, first pregnancy ; membranes ruptured for 48 hours and the liquor became foul-smelling. Delivery was normal, but the patient was pyrexial for two days after delivery. Both eyes of the baby were sticky at birth and became more purulent. The infection was treated with chloramphenicol eye-drops, being cleared in 48 hours. The baby was pyrexial for three days and was treated with Ampiclox. Serum from both mother and baby, collected soon after delivery, contained complement-fixing antibody to $M$. hominis to a titre of $1 / 10$. Second specimens of serum were not available for testing.

Case 6.-Aged 30, separated from husband, seven previous pregnancies ; membranes ruptured for 10 hours before a normal delivery. Both of the baby's eyes were watery, with desquamation of the skin around the eyes on the day after delivery. At birth, serum from the baby had a complement-fixation titre of $1 / 10$ to $M$. hominis and the metabolism-inhibiting antibody titre was 1/4. Sixteen days later the antibody titres were unchanged. Maternal antibody levels were the same.

Case 7.-Aged 30, single, first pregnancy ; membranes ruptured for one hour followed by normal delivery. The left eye of the baby became sticky on the day following birth; this cleared after two days' treatment with saline swabs,

Case 8.-Aged 17, single, first pregnancy ; membranes ruptured for 48 hours. The delivery was normal and there was no postpartum fever. Both eyes of the baby were purulent and were treated with chloramphenicol eye-drops. A T-strain mycoplasma was isolated in addition to $M$. hominis from the baby's eyes.

\section{Comment}

In the maternity unit of this hospital there are approximately 2,500 deliveries a year and $M$. hominis can be isolated from vaginal swabs from about $20 \%$ of antenatal patients (Jones, 1967b). Thus only in a minority (1-2\%) of patients who carry $M$. hominis in the vagina does the organism become transmitted to the conjunctiva of the baby. The clinical severity of the eye infection varied from "frankly purulent" to "slightly sticky." In the more severe infections where the eyes were sticky at birth there was a prolonged period when the membranes were ruptured and the liquor became infected before delivery. The remaining deliveries were normal and of short duration, and presumably the conjunctiva was infected during delivery; in these cases the onset of symptoms was within 24 hours of birth. In one baby, from whom two specimens of serum were collected, no antibody response was detected.

It is not normal practice to culture eye swabs for mycoplasmas, so that the general incidence of these infections is not yet known. It is probable that a proportion of swabs that fail to yield any of the bacteria usually associated with neonatal eye infection would show a growth of mycoplasma on further incubation. The use of selective media may lead to the discovery that other Mycoplasma species also cause eye infections, as a T-strain mycoplasma was also isolated from one of the cases described.

The social status of the patients is worthy of note, as seven of the mothers were single or had separated from their 
husbands, and the prevalence of $M$. hominis in the genital tract is probably associated with sexual promiscuity.

Though mycoplasmas may cause conjunctivitis in animals (Cole et al., 1967) reports that they may do so in man are scanty. Arm et al. (1966) isolated an unidentified mycoplasma from the conjunctiva of a 5-year-old boy with conjunctivitis. Our findings indicate that mycoplasma infections of the eye in humans do occur, at least among neonates, and may be commoner than is realized.

This investigation was supported by a grant from the Manchester Regional Hospital Board.
REFERENCES

Arm, H. G., Woolridge, R. L., Cheng, K-H., and Chang, I-H. (1966). Amer. F. Ophthal., 62, 1125 .

Clyde, W. A. (1964). F. Immunol., 92, 958.

Cole B. C. Golighty, I and Ward, J. R. (1967). F. Bact., 94, 1451. Hayflick, L., and Standbridge, E. (1967). Ann. N.Y. Acad. Sci., 143, 608.

Hoogendijk, J. L., De Bruijne, J. I., and Herderscheĉ, D. (1965). Ned. T. Geneesk. 109, 1433

Jones, D. M. (1967a). Brit. med. F., 1, 338.

Jones, D. M. (1967b). F. clin. Path., 20, 633

Pease, P., Rogers, K. B., and Cole, B. C.' (1967). F. Path. Bact., 94, 460. Slingerland, D. W., and Morgan, H. R. (1952). F. Amer. med. Ass., 150, 1309.

Stokes, E. J. (1955). Lancet, 1, 276.

Tully, J. G., Brown, M. S., Sheagren, J. N., Young, V. M., and Wolff, S. M. (1965). New Engl. F. Med., 273, 648.

\title{
Carcinoma of Bronchus and the Smoking Habit in Rhodesian Africans
}

\author{
MICHAEL GELFAND,* C.B.E., M.D., F.R.C.P. ; A. J. P. GRAHAM, $†$ M.B., F.R.C.s. \\ ELAINE LIGHTMAN, B.A., CERT.STATS.
}

Brit. med. F., 1968, 3, 468-469

\begin{abstract}
Cummary : Comparison of the smoking habits of 32 adult male Africans with carcinoma of the bronchus and 32 controls showed that $87.5 \%$ of the patients with lung cancer were cigarette smokers compared with only $22 \%$ of the controls. The distribution of histological types of growth confirmed findings by other workers.

The absence of atmospheric pollution in Rhodesia makes it likely that cigarette-smoking is the most important causative factor in the aetiology of lung cancer among Rhodesian Africans. Further work is needed to determine the level of consumption of cigarettes and type of smoking habits which lead to a serious risk of cancer.
\end{abstract}

\section{Introduction}

No serious argument can be levelled against the association of carcinoma of the bronchus with smoking, more particularly that of the cigarette (Doll and Hill, 1950). It is true that there are many who consider as more responsible the carcinogens in smoke which has polluted the atmosphere in city or urban areas. But the presence of a carcinogenic hydrocarbon in cigarette cmoke is probably a far more potent factor. The contents of the atmosphere were compared by Stocks and Campbell (1955) in two areas in England-one an almost permanently smoke-bound city, the other a semi-urban community in a wholly rural part of north Wales. In a rural community, where the atmospheric pollution is minimal, the incidence of lung cancer increases progressively with the number of cigarettes smoked. The death rate from lung cancer of heavy cigarette smokers (over 35 a day) was 20 times greater than that of non-smokers and eight times greater than that of pipe smokers. Among non-smokers the lung cancer rate was much higher in the urban than in the rural areas, the urban lung cancer rate being eight times higher than the rural rate. However, as cigarette-smoking became heavier the differences tended to disappear.

Stocks and Campbell (1955) drew attention to the close correlation between the concentrations of 3:4-benzpyrene in

* Department of Medicine, University College of Rhodesia. t Cardiothoracic Surgeon, Harare Hospital, Salisbury, Rhodesia. the air (about 10 times higher in Liverpool than in Wales) and to the relative incidence of lung cancer in non-smokers (about seven times as high in Liverpool as in Wales). As one would expect, the concentration appears to increase with urbanization, depending on the proximity of industry, houses, and motor vehicles. Although they are hesitant to incriminate 3:4-benzpyrene as the villain of the piece, it is clear that Stocks and Campbell would evince little surprise if a close correlation were found between this carcinogen and lung cancer.

The African in Rhodesia smoked tobacco before Eurepeans entered the country in 1890. They grew their own leaf and had elaborate methods of preparing the tobacco as a "cigar," for the pipe, or for snuff. However, with the introduction of factory-made cigarettes, the African began to buy his cigarettes, but sometimes, especially when he lived in the rural villages, he continued to grow his own tobacco and rolled it into a cigarette with any paper he could find. This is still quite commonly done, much depending on his own finances. Few Rhodesian Africans have taken to the pipe. Typically, too, the cigarette is smoked to its very end.

The atmosphere in the towns of Rhodesia is, for practical purposes, purer than in the industrial towns of Europe, since pollution from industrial smoke in Rhodesia is very slight. Nor do we believe that the pollution from motor vehicles is so heavy in Rhodesia as to be a factor in the causation of lung disease. Indeed, the atmosphere in Central Africa would seem to be remarkably healthy. Veld fires are frequent and extensive, but it is very doubtful whether the atmosphere is ever polluted long enough for this to be of any direct consequence. In any case the fires are very seasonal and focal.

Africans living in tribal areas are in the habit of sitting close to the fires in their huts, and it is possible that they often sleep in a smoky atmosphere. However, sitting by smoking fires is common in countries such as the Congo, where lung cancer is said to be very rare.

One of us (M.G.) visited the Congo (Leopoldville) and Nigeria (Ibadan), where very few cigarettes are smoked by the African population because tobacco is grown only with the greatest difficulty, and found that bronchogenic carcinoma was rarely encountered. However, this is not the case in Rhodesia, where cigarette-smoking is common among the Africans. We 